\title{
Cross-sectional consumption-based asset pricing: The importance of consumption timing and the inclusion of severe crises
}

\section{Tom Engsted and Stig V. Møller}

School of Economics and Management

Aarhus University

Bartholins Allé 10, Building 1322, DK-8000 Aarhus C Denmark 


\title{
Cross-sectional consumption-based asset pricing: The importance of consumption timing and the inclusion of severe crises*
}

\author{
Tom Engsted ${ }^{\dagger}$ and Stig V. Møller
}

\begin{abstract}
By using a beginning-of-period timing convention for consumption, and by including the Great Depression years in the analysis, we show that on annual data from 1926 to 2009 a standard contemporaneous consumption risk model goes a long way in explaining the size and value premiums in cross-sectional data that include both the Fama-French portfolios and industry portfolios. A long run consumption risk variant of the model also produces a high cross-sectional fit. In addition, the equity premium puzzle is significantly reduced in the models. We argue that in evaluating consumption based models, it is important to include both boom and crises periods, i.e. periods with severe consumption declines as well as periods with strong growth, and that the standard post-war data sample may not be well suited in this respect.
\end{abstract}

Keywords: Consumption-based model, long-run risk, the Great Depression, beginning-of-period timing convention, equity premium puzzle, Fama-French and industry portfolios, size and value premiums, GMM, cross-sectional $R^{2}$.

JEL codes: G12

\footnotetext{
*First version: January 2011. This research is supported by CREATES, funded by the Danish National Research Foundation.

${ }^{\dagger}$ CREATES and School of Economics and Management, Aarhus University, Bartholins allé 10, DK8000 Aarhus C., Denmark. E-mail: tengsted@creates.au.dk.

${ }^{\ddagger}$ CREATES and Finance Research Group, Aarhus School of Business, Aarhus University, Fuglesangs allé 4, DK-8210 Aarhus V., Denmark. E-mail: svm@asb.dk.
} 


\section{Introduction}

Since the seminal studies by Grossman and Shiller (1981), Hansen and Singleton (1982, 1983), and Mehra and Prescott (1985), a central research topic in empirical asset pricing has been to investigate the extent to which equilibrium expected returns can be explained by reference to their covariation with aggregate consumption. Initially the consumptionbased framework based on a simple constant relative risk-aversion utility specification was not an empirical success. Recently, however, various extensions of the basic consumptionbased framework have been more successful, see e.g. Cochrane (2007) for a detailed survey of these developments.

In a cross-sectional context it has become standard practice to evaluate a given asset pricing model against the 25 Fama-French portfolios sorted on size and value (Fama and French, 1993). Several recent consumption-based models have claimed success based on such an evaluation, e.g. Lettau and Ludvigson (2001), Julliard (2005), Lustig and van Nieuwerburgh (2005), and Yogo (2006). In these studies focus is on contemporaneous consumption risk at relatively high frequencies (typically quarterly horizon), and given the initial lack of empirical success of the consumption based framework, the recent more successful results are reassuring for this framework.

However, the above mentioned studies are all subject to the critique put forward by Lewellen, Nagel, and Shanken (2010), i.e., the 25 Fama-French portfolios have a very strong factor structure such that they basically reduce to the underlying three factors in the Fama-French three-factor model, and any model with factors that are (weakly) correlated with one or more of the Fama-French factors will automatically generate high cross-sectional $R^{2}$ 's and low pricing errors.

Another recent extension of the basic consumption based framework that has delivered promising results is the modeling of long-run consumption risk, e.g. Daniel and Marshall (1997), Bansal and Yaron (2004), Parker and Julliard (2005), and Hansen, Heaton, and Li (2008). Daniel and Marshall (1997) find higher correlations between long-horizon returns and long-horizon consumption growth than between their short-horizon counterparts, and Bansal and Yaron (2004) show that a small long-run predictable component in 
consumption growth, together with time-varying consumption volatility, goes a long way in explaining key empirical asset pricing puzzles in a consumption-based model based on Epstein and Zin (1989) preferences. Parker and Julliard (2005) explicitly investigate a moment condition expressed in terms of multi-period returns and consumption growth, and based on the standard constant relative risk-aversion specification they find that at multi-year horizons consumption risk explains a large fraction of the cross-sectional variation in stock returns. Parker and Julliard evaluate their long-run risk model crosssectionally using the 25 Fama-French portfolios. This implies that their results may be subject to the criticism of Lewellen, Nagel, and Shanken (2010) and, indeed, Grammig, Schrimpf, and Schuppli (2009) find that by extending the set of portfolios to include industry portfolios, the evidence in support of the Parker-Julliard model becomes much weaker.

In the present paper we provide new empirical evidence in support of the consumption based asset pricing framework. We make three main contributions to the existing literature. First, we show that if one adopts the beginning-of-period timing assumption for consumption, as in Campbell (2003), then contemporaneous consumption risk in a standard model with constant relative risk-aversion explains a much larger fraction of the cross-sectional variation in asset returns than when an end-of-period timing assumption for consumption is imposed. This is interesting because most existing studies have adopted the end-of-period timing convention, although there are no definite theoretical reasons for choosing the end-of-period convention over the beginning-of-period convention (cf. Campbell, 2003, pp. 813-814). We present arguments for using the beginning-ofperiod timing assumption, and we show that this minor change in the measurement of consumption has a big impact on the consumption-based model's ability to account for the cross-sectional variation in returns.

Second, we show that in both short-horizon (contemporaneous) and long-horizon consumption risk models there is much more empirical support for the models if one includes crises periods in the analysis, i.e. periods with severe negative consumption growth rates. Our analysis uses annual data for the period 1926-2009, i.e. our sample includes the pre-war period that includes the Great Depression. This is in contrast 
to most earlier studies that examine consumption-based model's cross-sectional pricing abilities; these studies typically use quarterly post-war data in which there are only few observations with negative consumption growth rates. We show that the results are very sensitive to including pre-war data in the analysis. Some may say that this is an argument against including pre-war data. By contrast we argue that in order to fully capture the consumption-based model's empirical pricing ability, one needs to include both boom and crises periods in the analysis, i.e. periods with severe consumption declines as well as periods with strong consumption growth. Including the Great Depression years in the analysis serves this purpose. Similarly, including the recent negative growth observations in 2008 and 2009, as a result of the financial crisis, may - all else equal - lead to better empirical performance of the consumption-based model. ${ }^{1}$

Third, we show that our main finding, i.e. that by including pre-war data in the analysis the standard consumption-based model explains a large part of the cross-sectional variation in returns, also holds if industry portfolios are added to the Fama-French value and size portfolios. Thus, our results are not subject to the Lewellen, Nagel, and Shanken critique. This makes us confident that the relative success we obtain for the consumptionbased model is not the result of setting a too low hurdle to meet in the empirical analysis, cf. Lewellen, Nagel, and Shanken (2010, p.176). ${ }^{2}$

Our results imply that in contrast to what is usually believed, the standard contemporaneous consumption risk model explains to a large extent both the size premium and the value premium. Using a beginning-of-period timing convention for consumption and including severe crises periods in the analysis are the main driving forces behind these results. In addition, these features of the model significantly reduce the equity premium puzzle.

\footnotetext{
${ }^{1}$ In settings different from ours Bianchi (2010) and Gallant and Aldrich (2010) have also stressed the importance of including 'rare events' and 'extreme consumption fluctuations' when empirically fitting asset pricing models to data. They also include the Great Depression years in their analyses. This discussion is obviously related to the 'rare events' analyses in Reitz (1988) and Barro (2006, 2009), among others.

${ }^{2}$ On post war data Møller (2009) investigates the Campbell and Cochrane (1999) habit persistence model's ability to explain the cross-sectional variation in the 25 Fama-French portfolios plus 10 industry portfolios, following the suggestion in Lewellen, Nagel, and Shanken (2010). He finds that the model explains the size premium but fails to explain the value premium.
} 
The rest of the paper is organized as follows. Section 2 presents the model and estimation procedure. Section 3 reports the empirical results using portfolios sorted along size, value, and industry dimensions. Finally, section 4 offers some concluding remarks.

\section{Model and estimation procedure}

In this section we describe our model and estimation procedure. As we follow the approach of Parker and Julliard (2005), the description will be very brief.

\subsection{The model}

Consumption-based asset pricing theory implies that investors make consumption and investment decisions in order to maximize expected lifetime utility. With standard constant relative risk aversion utility, and using the law of iterated expectations, we can state the maximization condition as the following unconditional moment condition:

$$
E\left[\delta C_{t}^{-\gamma} R_{i, t}\right]-E\left[\delta C_{t}^{-\gamma} R_{t}^{f}\right]=0
$$

where $R_{i, t}$ is the gross return of investing in the risky asset $i, R_{t}^{f}$ is the risk-free rate, $\delta$ is the subjective discount factor, and $\gamma$ is the relative risk aversion coefficient. Then, following the approach of Parker and Julliard (2005), we use the $S$-period moment condition for the risk-free rate:

$$
C_{t}^{-\gamma}=E\left[\delta^{S} C_{t+S}^{-\gamma} R_{t, t+S}^{f}\right]
$$

and substitute out $C_{t}^{-\gamma}$ in Eq. (1). This gives rise to the following relation:

$$
E\left[M_{t}^{S} R_{i, t}^{e}\right]=0
$$


where $R_{i, t}^{e}=R_{i, t}-R_{t}^{f}$ is the excess return on asset $i$ and $M_{t}^{S}=R_{t, t+S}^{f}\left(\frac{C_{t+S}}{C_{t-1}}\right)^{-\gamma}$ is the stochastic discount factor. ${ }^{3}$ It then follows from Eq. (3) that we can express the expected excess return as:

$$
E\left[R_{i, t}^{e}\right]=-\frac{\operatorname{cov}\left[M_{t}^{S}, R_{i, t}^{e}\right]}{E\left[M_{t}^{S}\right]},
$$

which illustrates that the expected excess return on a given asset is determined by its exposure to consumption risk. With $S>0$, we are in the long-horizon consumption risk framework of Parker and Julliard where one-period excess returns are matched with future consumption growth rates, while with $S=0$ we obtain the standard model based on contemporaneous consumption risk, where one-period excess returns are matched with one-period consumption growth rates.

Parker and Julliard denote $\operatorname{cov}\left[M_{t}^{S}, R_{i, t}^{e}\right]$ with $S>0$ 'ultimate consumption risk', and they argue that this measure may be a better measure of the risk of an asset than the traditional measure where $S=0$, due to e.g. adjustment costs that induce slow adjustment in consumption (Parker and Julliard, 2005, p.186). On post war US data they indeed find that increasing $S$ leads to higher covariances. Below we discuss this further in relation with using either an end-of-period or a beginning-of-period timing assumption for consumption.

\subsection{Estimation procedure}

We estimate the model using Hansen's (1982) generalized method of moments (GMM). From Eq. (4), we form the following moment conditions:

$$
\begin{aligned}
0_{N} & =E\left[R_{t}^{e}-\alpha 1_{N}+\frac{\left(M_{t}^{S}-\mu\right) R_{t}^{e}}{\mu}\right] \\
0 & =E\left[M_{t}^{S}-\mu\right]
\end{aligned}
$$

where the vector $R_{t}^{e}$ contains excess returns on $N$ assets, $1_{N}$ is an $N$-vector of ones, $\alpha$ is the mean pricing error, and $\mu$ is the mean stochastic discount factor. Following

\footnotetext{
${ }^{3}$ Note that we have divided with $C_{t-1}^{-\gamma}$ to obtain stationarity and that $\delta$ does not matter when working with excess returns.
} 
Parker and Julliard (2005) and Malloy, Moskowitz, and Vissing-Jørgensen (2009), among others, we include a constant $\alpha$ in the moment conditions. This implies that a common underprediction (or overprediction) of the overall level of returns is allowed such that the ability of the model to fit the cross section of returns is separated from its ability to fit the equity premium.

Based on a sample size of $T$ observations, we collect the $N+1$ sample moments in $g_{T}$ and estimate the parameter vector $\theta=(\mu, \gamma, \alpha)^{\prime}$ by minimizing the quadratic form:

$$
g_{T}{ }^{\prime} W g_{T}
$$

where $W$ is a positive definite weighting matrix. The inverse of the covariance matrix of the moments gives the statistically optimal weighting matrix as it provides the smallest possible variances of the estimated parameters. However, due to the fact that the statistically optimal weighting matrix places the highest weight on the linear combination of moments with the lowest variance, it may produce uninteresting weights in an economic sense. Rather than using the statistically optimal weighting matrix, we therefore use the identity matrix to ensure that GMM pays equal attention to each asset in the cross section. In particular, we use the following weighting matrix:

$$
W=\left[\begin{array}{cc}
I_{N} & 0 \\
0 & k
\end{array}\right],
$$

where $I_{N}$ is an $N$ times $N$ identity matrix that places a weight of 1 on each asset in the cross section, and $k$ is set equal to a very large number such that we make sure that our empirical results are not due to misestimation of the mean stochastic discount factor. ${ }^{4}$ As we use a suboptimal weighting matrix in a statistical sense, the usual way of calculating standard errors and the $J$-test of overidentifying restrictions does not apply. Hence, we use the general formulas that apply to suboptimal estimates as described in Cochrane (Chap. 11, 2005). The $J$-test is asymptotically $\chi^{2}$ distributed with $N+1-3$ degrees of freedom.

\footnotetext{
${ }^{4}$ This approach follows Parker and Julliard (2005), Grammig, Schrimpf, and Schuppli (2009), Malloy, Moskowitz, and Vissing-Jørgensen (2009), among others.
} 
Note that due to the inclusion of $\alpha$ in the moments conditions (5), one should be careful in interpreting a low estimated value of $\gamma$ as implying low risk aversion. Only if $\alpha=0$ does a low value of $\gamma$ indicate low risk aversion. As explained above, $\alpha$ is included to separate the evaluation of the model's ability to fit the cross-section of returns from the evaluation of the model's ability to explain the equity premium. As a consequence, in section 3 we will not put too much weight on the estimated $\gamma$ values. Instead, crosssectional $R^{2}$ and plots of realized versus model predicted mean returns will play a key role in evaluating the models.

\section{Empirical results}

\subsection{Data and summary statistics}

We use two sample periods: A Great Depression sample that runs from 1926 to 2009 (the cross-sectional return data is available starting from 1926), and a post-war sample that runs from 1950 to 2009. Given that we work with a long sample that includes the Great Depression, we have to use annual observations, whereas previous consumption-based studies typically have used quarterly post-war data. An advantage of using quarterly data is more data points, but a drawback is seasonal adjustment which may give rise to measurement error and potentially disrupt the empirical link between consumption and stock returns.

We estimate the model on a number of different portfolio sets sorted by value, size and industry. All portfolios are obtained from Kenneth French's website. Our proxy for the risk-free rate is based on the annual return on a 3-month T-bill rate available from CRSP. We measure consumption as real per capita expenditures on nondurable goods and services and use the same consumption data as in Campbell (2003), which is available at John Campbell's website. ${ }^{5}$ The data is available from 1926 to 1997 and in the remaining period of our sample (1998 to 2009), we use the consumption data from the

\footnotetext{
${ }^{5}$ The same data is used in other consumption-based studies such as in Campbell and Cochrane (1999).
} 
NIPA tables. ${ }^{6}$ Our empirical results are robust towards the measure of consumption. For instance, we have also used total consumption, which is available for the entire sample period from Robert Shiller's website. If we use total consumption (as Parker and Julliard (2005) do in their Table 3), we obtain very similar results as the ones we report below based on non-durables and services.

We consider $S=0,1,2,3$, and 4 years in Eq. (4), but the final return observation is always in 2005 to ensure that it is possible to compare the results across different values of $S$. When we consider future consumption risk $(S>0)$, we apply the standard end-of-period timing convention that consumption during year $t$ takes place at the end of year $t$, whereas when we consider contemporaneous consumption risk $(S=0)$, we apply both the standard end-of-period timing assumption and Campbell's (2003) beginning-ofperiod timing assumption that consumption during year $t$ takes place at the beginning of year $t$.

There are arguments for and against both timing assumptions. The standard endof-period convention is typically used because, as e.g. Julliard and Ghosh (2008, p.11) explain, "We make this choice so that the entire period that $C_{t}$ covers is contained in the information set of the agent before the time $t+1$ return is realized." This is a valid argument, but the end-of-period assumption implies that when new information arrives during time $t$, and consumption is slow to adjust due to e.g. adjustment costs (as argued by Parker and Julliard, 2005), then investors may only be able to adjust their consumption fully during time $t+1$. This will be captured by using the beginning-of-period assumption. Thus, the beginning-of-period assumption is a crude way of taking into account - within the contemporaneous consumption risk framework - a possible one-period lag in adjusting parts of consumption. In the end it is an empirical question which timing assumption produces the best fit for the model. In a pure time series context, Campbell (2003) shows that beginning-of-period consumption produces higher contemporaneous correlation with the aggregate market return than end-of-period consumption. Below we

\footnotetext{
${ }^{6}$ Based on the NIPA tables, we measure consumption in the following way. Real consumption is obtained as personal consumption expenditures on nondurable goods (Table 2.3.5, line 8) divided with the price index for nondurable goods (Table 2.3.4, line 8) plus personal consumption expenditures on services (Table 2.3.5, line 13) divided with the price index for services (Table 2.3.4, line 13). Per capita real consumption is calculated based on the population numbers from Table 2.1, line 39 .
} 
examine the importance of using beginning-of-period consumption when it comes to the cross section of expected returns.

Table 1 gives summary statistics of the alternative consumption measures that we apply in our analysis. As we would expect, the mean and volatility of the growth rate in real per capita consumption increase with the horizon $S$. For each horizon, the mean consumption growth rate is rather similar in magnitude across the two samples, but in general slightly lower in the Great Depression sample. The table also shows that the consumption growth rates are more volatile when we extend the sample period to include the Great Depression; for instance, the one-year consumption growth volatility is $2.3 \%$ in the Great Depression sample relative to $1.1 \%$ in the post-war sample. The growth rates in consumption also become substantially more correlated with the stock market when we include the Great Depression years. Note that with the Campbell timing assumption the correlation with the stock market increases to an impressive $59.8 \%$ based on the Great Depression sample relative to $39.8 \%$ based on the post-war sample. The end-of-period and Parker-Julliard measures also produce higher correlations with the stock market when we take into account the Great Depression, but they are not nearly as high as with the Campbell beginning-of-period measure.

Overall, it is evident that the correlation of consumption growth with the stock market and the consumption growth volatility depend strongly upon the measure of consumption and the sample period used. Looking at the entire sample, the most dramatic drops in consumption were all related to the period of the Great Depression where we saw growth rates in consumption of $-2 \%$ or less in the years $1930-1933(-6.8 \%$ in 1930 and $-8.8 \%$ in 1932). Such significant drops in consumption have not taken place in the post-war period. The recent 'Great Recession' showed growth rates of $-0.6 \%$ in 2008 and $-1.0 \%$ in 2009. Over the whole period 1926-2009 with 83 annual observations, twelve years show negative consumption growth, seven of which occur in the period up to 1950. Our results show that the consumption growth rate becomes not only more volatile, but also more correlated with the stock market in times of severe economic crises such as during the Great Depression.

We now turn to summary statistics of the stock portfolios we use in our estimations. 
First, in Table 2 we show summary statistics for 10 decile portfolios formed on size. The table illustrates the well-known empirical fact that small firms earn higher returns than large firms, and that small firm returns are more variable than large firm returns. In fact, in the Great Depression sample the average excess return on the portfolio with the smallest firms is more than twice as large as that of the portfolio with the largest firms. To get an initial impression of the model's ability to explain the small-firm effect, the table also reports consumption growth covariances. When we consider the postwar sample, we see that the contemporaneous covariances based on the end-of-period convention $(S=0)$ are either close to zero or negative. Thus, with $S=0$ it seems that the model is completely unable to explain the strong cross-sectional variation in returns on size-based portfolios. The magnitude and pattern of the covariances improve when we use either beginning-of-period consumption $\left(S=0^{*}\right)$ or future consumption $(S>0)$, but the covariances are in general low in the post-war sample. When we use the Great Depression sample, we obtain much larger covariances. Most interestingly, we observe that the beginning-of-period measure produces the right pattern in contemporaneous covariances: firms that on average earn higher returns also have higher covariances. This suggests that standard contemporaneous consumption risk might actually be successful in explaining the small-firm effect if we take into account the Great Depression.

Besides the small-firm effect, we are also interested in examining the value effect. Table 3 shows summary statistics for 10 decile portfolios formed on book-to-market. The mean excess return increases monotonically along the value dimension such that value stocks with high book-to-market ratios earn a higher risk premium than growth stocks with low book-to-market ratios. In both the Great Depression and post-war sample, the portfolio with the highest book-to-market ratio produces an average excess return that is around twice as large as that of the portfolio with the lowest book-to-market ratio. By looking at the post-war sample, we once again note that the covariances are close to zero and sometimes even negative with $S=0$. With beginning-of-period consumption $\left(S=0^{*}\right)$ as well as future consumption $(S>0)$, the covariances tend to increase in the value dimension (i.e. move in the right direction), but the covariances are in general rather small. The covariances increase substantially when we include 
pre-war data. Furthermore, the contemporaneous covariances based on beginning-ofperiod consumption tend to be larger for high book-to-market firms than they are for low book-to-market firms, suggesting that the value premium might actually be related to contemporaneous consumption risk after all. In addition, consumption covariances are in general larger for $S>0$ than for $S=0$ and $0^{*}$.

In all our GMM estimations, we follow the suggestion of Lewellen, Nagel, and Shanken (2010) and include industry sorted portfolios in order to expand the portfolio set beyond the value and size dimensions. Table 4 shows summary statistics for 10 industry sorted portfolios. $^{7}$ Unlike the size-based and the value-based portfolios, the industry-based portfolios do not show strong cross-sectional variation in the average returns (and this is the case in both samples). However, just like in Tables 2 and 3, Table 4 shows that the beginning-of-period measure produces much larger contemporaneous covariances than the end-of-period measure and that the covariances in general are much larger in the Great Depression sample relative to the post-war sample. Again, in the former sample consumption covariances are in general larger for $S>0$ than for $S=0$ and $0^{*}$.

\subsection{Estimation results}

In this section we present GMM estimation results. First, we examine the model's pricing abilities along the size dimension by estimating the model on 10 size-based portfolios joint with 10 industry-based portfolios. Second, we examine the model's pricing abilities along the value dimension by estimating the model on 10 value-based portfolios joint with 10 industry-based portfolios. Finally, we estimate the model on the 6 Fama-French double-sorted portfolios joint with 5 industry-based portfolios. The use of double-sorted portfolios allows us to examine whether the model has the ability to simultaneously account for the size and value premiums.

\footnotetext{
${ }^{7}$ The 10 industries are Consumer Nondurables, Consumer Durables, Manufacturing, Energy, High Tech Business Equipment, Telecom, Shops, Health, Utilities, and Others (e.g. Mines, Construction, Transportation, Hotels, Entertainment, Finance).
} 


\subsubsection{Size-based portfolios}

Table 5 shows GMM results using 10 size portfolios and 10 industry portfolios as test assets. Looking at the post-war results, we see that the model fit is rather poor for all consumption risk measures. The risk aversion coefficient is statistically insignificant in all cases and the cross-sectional $R^{2}$ 's are generally low. ${ }^{8}$ The mean pricing error, $\alpha$, is around $7-9 \%$ and statistically significant, which is an illustration of the equity premium puzzle. The best cross-sectional fit is obtained with beginning-of-period contemporaneous consumption risk, which yields an $R^{2}$ of $21 \% .^{9}$

Next, we focus the attention on the Great Depression sample. We see that endof-period contemporaneous consumption risk is still unable to explain the size effect as it produces an $R^{2}$ of $0 \%$. In contrast, an $R^{2}$ of $74 \%$ suggests that contemporaneous consumption risk based on the beginning-of-period convention works quite well in explaining the variation in returns on size-based portfolios. The Parker-Julliard long-run risk model also produces much larger $R^{2}$ 's in the Great Depression sample. The best fit with long-horizon consumption risk is obtained with $S=3$ years, which gives an $R^{2}$ of $81 \%$.

The common underprediction of the overall level of returns is, except with $S=0$, much lower in the Great Depression sample and the estimated values of $\alpha$ are statistically insignificant (for $S=4$ the pricing error is marginally significant at a $5 \%$ level). This indicates that the equity premium puzzle is not as severe when we take into account the crisis years of the Great Depression. The risk aversion coefficient is in most cases still insignificant at conventional significance levels, but with $S=0^{*}$ the parameter is

${ }^{8}$ We calculate the cross-sectional $R^{2}$ as in Parker and Julliard (2005):

$$
R^{2}=1-\frac{\operatorname{Var}\left(\bar{R}_{i}^{e}-\hat{R}_{i}^{e}\right)}{\operatorname{Var}\left(\bar{R}_{i}^{e}\right)},
$$

where $\bar{R}_{i}^{e}$ is the mean excess return on asset $i$ and $\hat{R}_{i}^{e}$ is the model predicted mean excess return on asset $i$.

${ }^{9}$ Given the close to zero covariances in the post-war part of Table 2, one may be puzzled by the very low $\gamma$ estimates for many of the $S$ values in the post-war part of Table 5 . The explanation is the high estimated values of $\alpha$. Low covariances result in high $\alpha$ values rather than high $\gamma$ values. If we impose $\alpha=0$, the estimated $\gamma$ 's become very high in the post-war sample. 
significantly different from 0 at the $10 \%$ level. Looking at the $J$-test of overidentifying restrictions, we also see that the model is only marginally rejected at the $5 \%$ level with $S=0^{*}$, but is strongly rejected in all other cases. Naturally we should not expect the model to fit perfectly, so statistical rejections are expected unless the tests lack power.

The common perception in the literature is that standard contemporaneous consumption risk is unable to address the size premium. We arrive at the opposite conclusion. Our conclusion hinges on the combination of two premises: i) the use of the Campbell beginning-of-period timing convention, and ii) the inclusion of the Great Depression years. To illustrate this further, Figure 1 plots model predicted mean excess returns against realized mean excess returns. A perfect fit implies that all points lie along the 45-degree line. If a point is below (above) the line, the model underpredicts (overpredicts) the excess return on the given asset. Figures $1 \mathrm{~A}$ and $1 \mathrm{C}$ demonstrate that standard end-of-period contemporaneous consumption risk is not useful in explaining the crosssectional variation in returns on size-based and industry-based portfolios. Basically, the model does not generate any action along the size and industry dimensions at all. This is the case in both samples. By looking at Figures 1B and 1D, however, we see that the cross-sectional fit improves when contemporaneous consumption risk is measured based upon the Campbell timing convention. As Figure 1B illustrates, this is especially visible when we consider the Great Depression sample where the model explains a large part of the cross-sectional variation in returns.

These results underscore the importance of including both periods with high consumption growth and periods with strong consumption declines when evaluating consumption based models. If agents base their decisions on the perception that consumption growth is very volatile, it is important to include in the analysis data that contain large fluctuations in consumption growth. The post-war sample - which is used in most of the existing cross-sectional literature - contains many high growth observations but only a few observations of strongly negative consumption growth. If people are aware of the Great Depression years and find it conceivable that severe crises will occur now and then, analyses using only post-war data will not capture the true expected returns and covariances perceived by the public and, hence, such analyses will misrepresent peoples 
actual behavior. The recent 'Great Recession', with negative consumption growth in 2008 and 2009, shows that severe crises are not eliminated in modern times, thus justifying working with data samples that include severe crises. ${ }^{10,11}$

\subsubsection{Value-based portfolios}

Table 6 shows the results of estimating the models on 10 value-based portfolios joint with 10 industry-based portfolios. First, we consider the post-war sample results. Once again, the risk aversion coefficients are statistically insignificant, while the mean pricing errors, $\alpha$, are significant and large. In addition, the relatively low cross-sectional $R^{2}$ 's imply that it is not possible to explain the value premium for any consumption measure.

Turning to the Great Depression sample, we observe that except for $S=0$ the $\alpha$ 's are now smaller and statistically insignificant (i.e. the same pattern as in Table 5). The cross-sectional fit is also improved by including the Great Depression in the sample. Contemporaneous consumption risk now works reasonably well in explaining the value premium, but only if we use beginning-of-period consumption. With $S=0^{*}$ the $R^{2}$ is $52 \%$, while the fit of the model completely deteriorates with $S=0$ as the $R^{2}$ is only 4\%. Including the Great Depression years also implies that long-horizon consumption risk is able to explain a large part of the value premium. Once again, we see that $S=3$ generates the best fit with an $R^{2}$ of $68 \%$.

Many empirical studies have shown that contemporaneous consumption risk is unable to address the value premium. In contrast, we find that contemporaneous consumption risk works reasonably well when we impose the Campbell timing convention and use a long sample that includes the Great Depression. We illustrate this in Figure 2. If we use

\footnotetext{
${ }^{10}$ Our data sample includes the years 2008 and 2009. However, these two observations together with the few other negative growth observations in the post-war sample, do not provide sufficient consumption volatility and covariance with returns to generate support for the basic consumption based asset pricing model in post-war data, as seen from Tables 5 to 7 with $S=3$ or 4 (note that since the final observation on $M_{t}^{S}$ is $t=2005$, the years 2008 and 2009 are not included for $S<3$ ).

${ }^{11}$ Julliard and Ghosh (2008) conduct an analysis similar in spirit to - but methodologically quite different from - ours and reach a very different conclusion, as they find that including rare events worsens the consumption based model's cross-sectional pricing abilities. However, in their cross-sectional analyses Julliard and Ghosh use only post-war data and they apply the end-of-period timing convention for consumption. In addition, they impose state probabilities different from their sample frequencies in order to rationalize the market equity premium with a low level of risk aversion.
} 
standard end-of-period consumption, contemporaneous consumption risk does not work well in explaining the value premium. As Figures $2 \mathrm{~A}$ and $2 \mathrm{C}$ show, this is the case in both samples. No matter what timing convention is used, the model is also unable to explain the value premium if we exclude the crises years of the Great Depression, see Figures $2 \mathrm{C}$ and 2D. However, when we use the Campbell convention and expand the sample to include the Great Depression, contemporaneous consumption risk is able to explain a relatively large fraction of the variation in returns on value- and industry-sorted returns. Figure 2B illustrates that the model still has some difficulties in fully explaining the value premium as it slightly overpredicts the returns on the low book-to-market portfolios and slightly underpredicts the returns on the high book-to-market portfolios, but the pricing errors are otherwise fairly small.

\subsubsection{Double-sorted portfolios}

As a further robustness check, we now examine whether the models are able to jointly handle a cross section consisting of both size, value and industry sorted portfolios. We do this by estimating the models on the 6 double-sorted size and value portfolios underlying the Fama and French (1993) factors SMB and HML joint with 5 industry-sorted portfolios. The 6 Fama-French portfolios contain roughly the same information as the 25 Fama-French portfolios, i.e. to reduce the number of moment conditions relative to the number of sample observations, we use the 6 rather than the 25 Fama-French portfolios.

Consistent with the above findings, Table 7 shows that the various consumption measures all have difficulties in explaining the cross-sectional variation in returns when we focus on the post-war sample period. But again, the cross-sectional performance improves substantially when we include the Great Depression period. Using beginning-ofperiod contemporaneous consumption risk gives an $R^{2}$ of $54 \%$, suggesting that the model matches the cross-sectional variation in mean returns on the size, value and industry portfolios reasonably well. The model fit, however, completely breaks down when we use standard end-of-period contemporaneous consumption risk as the cross-sectional $R^{2}$ drops to $7 \%$. As in Tables 5 and 6 , we see in Table 7 that the best performance is obtained when $S=3$, which yields an $R^{2}$ of $64 \%$. This also suggests that by including 
the Great Depression years in the sample, the Parker-Julliard long-run risk model is able to produce a reasonable fit of a joint cross section with both size, value and industry sorted portfolios, in contrast to the post-war results of Grammig, Schrimpf, and Schuppli (2009). In addition, including the data prior to 1950 significantly reduces the equity premium puzzle, as seen from the much lower $\alpha$ estimates compared to the $\alpha$ estimates in the 1950-2009 sample.

\section{Concluding remarks}

Recent research has partly rehabilitated the consumption-based framework to asset pricing by focusing on, among other things, non-separable utility functions (including habits) and long-horizon consumption risk. In this paper we have argued that even in the standard model with separable power utility and short-horizon (contemporaneous) consumption risk, there is much more empirical support for the consumption-based model than what is usually believed. Two specific features of our modeling exercise drive this conclusion: we apply a beginning-of-period timing assumption for consumption, and we include data from before World War II in the analysis.

It is well-known that in a pure time-series setting the 'equity premium puzzle' is reduced (but not fully solved) by using the beginning-of-period timing convention for consumption. We show that in a cross-sectional setting with size-, value-, and industrysorted stock portfolios, the standard consumption-based model with contemporaneous (one-year) consumption risk explains to a large extent the size and value premiums if we assume that consumption for year $t$ takes place at the beginning of year $t$. A further requirement for this result to hold is that we include pre-war data in the analysis. Including data from the Great Depression period, together with the beginning-of-period timing assumption, implies a cross-sectional $R^{2}$ from $52 \%$ to $74 \%$ depending on the portfolios included in the analysis. In a long-horizon setting with consumption growth

measured over several years, the cross-sectional model fit increases further to between $60 \%$ and $80 \%$. 
The relative success - compared to earlier studies - for the standard contemporaneous consumption risk model when including pre-war data in the analysis, underscores the importance of severe crises for the evaluation of such models. Our results highlight the necessity of including both periods with strong positive consumption growth and periods with strong negative consumption growth to account for the possibility that people perceive consumption growth to be much more volatile than what appears from looking exclusively at the post-war period.

\section{References}

Bansal, R., Yaron, A., 2004. Risks for the long run: A potential resolution of asset pricing puzzles. Journal of Finance 59, 1481-1509.

Barro, R.J., 2006. Rare disasters and asset markets in the twentieth century. Quarterly Journal of Economics 121, 823-866.

Barro, R.J., 2009. Rare disasters, asset prices, and welfare costs. American Economic Review 99, 243-264.

Bianchi, F., 2010. Rare events, financial crises, and the cross-section of asset returns. Working paper, Duke University.

Campbell, J.Y., 2003. Consumption-based asset pricing. In: Constantinides, G., Harris, M., Stulz, R., Handbook of the Economics of Finance, North Holland, Amsterdam, 803887.

Campbell, J.Y., Cochrane, J.H., 1999. By force of habit: A consumption based explanation of aggregate stock market behavior. Journal of Political Economy 107, 205-251.

Cochrane, J.H., 2005. Asset Pricing. Revised edition, Princeton University Press.

Cochrane, J.H., 2007. Financial markets and the real economy. In: Mehra, R. (Ed.), The Equity Premium, North Holland Handbook of Finance Series, North Holland, Amsterdam.

Daniel, K.D., Marshall, D., 1997. Equity-premium and risk-free-rate puzzles at long horizons. Macroeconomic Dynamics 1, 452-484.

Epstein, L.G., Zin, S.E.,1989. Substitution, risk aversion, and the temporal behavior of consumption and asset returns: A theoretical framework. Econometrica 57, 937-968. 
Fama, E., French, K., 1993. Common risk factors in the returns on stocks and bonds. Journal of Financial Economics 33, 3-56.

Gallant, R.A., Aldrich, E.M., 2010. Habit, long-run risks, prospect? A statistical inquiry. Working paper, Duke University.

Grammig, J., Schrimpf, A., Schuppli, M., 2009. Long-horizon consumption risk and the cross-section of returns: New tests and international evidence. European Journal of Finance $15,511-532$.

Grossman, S.J., Shiller, R.J., 1981. The determinants of the variability of stock market prices. American Economic Review Papers and Proceedings 71, 222-227.

Hansen, L.P., 1982. Large sample properties of generalized method of moments estimators. Econometrica 50, 1029-1054.

Hansen, L.P., Heaton, J., Lee, N., 2008. Consumption strikes back: Measuring long-run risk. Journal of Political Economy 116, 260-302.

Hansen, L.P., Singleton, K.J., 1982. Generalized instrumental variables estimation of nonlinear rational expectations models. Econometrica 50, 1269-1286.

Hansen, L.P., Singleton, K.J., 1983. Stochastic consumption, risk aversion, and the temporal behavior of asset returns. Journal of Political Economy 91, 249-68.

Julliard, C., 2005. Labor income risk and asset returns. Working paper, Princeton University.

Julliard, C., Ghosh, A., 2008. Can rare events explain the equity premium puzzle? Working paper, London School of Economics.

Lettau, M., Ludvigson, S., 2001. Resurrecting the (C)CAPM: A cross-sectional test when risk premia are time-varying. Journal of Political Economy 109, 1238-1287.

Lewellen, J., Nagel, S., Shanken, J., 2010. A skeptical appraisal of asset-pricing tests. Journal of Financial Economics 96, 175-194.

Lustig, H.N., van Nieuwerburgh, S.G., 2005. Housing collateral, consumption insurance, and risk premia: An empirical perspective. Journal of Finance 60, 1167-1219.

Malloy, C. J., Moskowitz, T.J, Vissing-Jørgensen, A., 2009. Long-run stockholder consumption risk and asset returns. Journal of Finance 64, 2427-2479. 
Mehra, R., Prescott, E., 1985. The equity premium: A puzzle. Journal of Monetary Economics 15, 145-161.

Møller, S.V., 2009. Habit persistence: Explaining cross-sectional variation in returns and time-varying expected returns. Journal of Empirical Finance 16, 525-536.

Newey, W.K., West, K.D., 1987. A simple, positive semidefinite, heteroskedasticity and autocorrelation consistent covariance matrix. Econometrica 55, 703-708.

Parker, J.A., Julliard, C., 2005. Consumption risk and the cross section of expected returns. Journal of Political Economy 113, 185-222.

Reitz, T.A., 1988. The equity risk premium: A solution. Journal of Monetary Economics $22,117-131$.

Yogo, M., 2006. A consumption-based explanation of expected stock returns. Journal of Finance 61, 539-580. 
Table 1. Summary statistics for consumption measures

\section{Great Depression sample 1926 - 2009}

Horizon

\begin{tabular}{lcccccc} 
& $S=0^{*}$ & $S=0$ & $S=1$ & $S=2$ & $S=3$ & $S=4$ \\
\cline { 2 - 7 } Mean & 1.7 & 1.7 & 3.5 & 5.3 & 7.1 & 8.9 \\
Vol & 2.3 & 2.3 & 3.9 & 5.2 & 6.1 & 6.8 \\
Corr. $R_{M}^{e}$ & 59.8 & 15.2 & 44.8 & 40.3 & 35.8 & 25.8 \\
\hline
\end{tabular}

Post-war sample 1950 - 2009

Horizon

\begin{tabular}{lcccccc} 
& $S=0^{*}$ & $S=0$ & $S=1$ & $S=2$ & $S=3$ & $S=4$ \\
\cline { 2 - 7 } Mean & 1.9 & 1.9 & 3.9 & 5.9 & 7.9 & 9.9 \\
Vol & 1.1 & 1.1 & 1.9 & 2.5 & 3.0 & 3.5 \\
Corr. $R_{M}^{e}$ & 39.8 & -2.8 & 22.3 & 14.5 & 7.2 & 4.2 \\
\hline
\end{tabular}

The table reports summary statistics of measures in consumption growth, $\frac{C_{t+S}}{C_{t-1}}$, where $S$ is the horizon. We indicate with a star, "*", when we use beginning-of-period consumption rather than standard end-of-period consumption. 'Mean' is the mean growth rate in real per capita consumption. 'Vol' is the standard deviation of the consumption growth rate. 'Corr. $R_{M}^{e}$ ' is the correlation coefficient with the excess return on the stock market (all in $\%)$. 
Table 2. Summary statistics for size-based portfolios

\begin{tabular}{|c|c|c|c|c|c|c|c|c|c|c|}
\hline & \multicolumn{10}{|c|}{ Great Depression sample 1926 - 2009} \\
\hline & \multicolumn{10}{|c|}{ Size portfolios } \\
\hline & $\mathrm{S} 1$ & $\mathrm{~S} 2$ & S3 & $\mathrm{S} 4$ & S5 & $\mathrm{S} 6$ & $\mathrm{~S} 7$ & $\mathrm{~S} 8$ & $\mathrm{~S} 9$ & S10 \\
\hline & \multicolumn{10}{|c|}{ Mean excess returns } \\
\hline & 16.0 & 13.1 & 12.5 & 11.9 & 11.0 & 10.9 & 10.6 & 9.4 & 8.8 & 7.0 \\
\hline & \multicolumn{10}{|c|}{$\underline{\text { Variances of excess returns }}$} \\
\hline & 16.7 & 12.6 & 10.5 & 8.9 & 7.6 & 7.2 & 6.3 & 5.3 & 4.7 & 3.7 \\
\hline Horizon & \multicolumn{10}{|c|}{ Consumption growth covariances } \\
\hline$S=0^{*}$ & 0.51 & 0.48 & 0.44 & 0.41 & 0.39 & 0.39 & 0.35 & 0.32 & 0.30 & 0.26 \\
\hline$S=0$ & 0.10 & 0.09 & 0.07 & 0.08 & 0.08 & 0.09 & 0.07 & 0.05 & 0.07 & 0.08 \\
\hline$S=1$ & 0.62 & 0.57 & 0.52 & 0.49 & 0.48 & 0.48 & 0.42 & 0.36 & 0.38 & 0.34 \\
\hline$S=2$ & 0.81 & 0.78 & 0.70 & 0.62 & 0.61 & 0.59 & 0.52 & 0.47 & 0.47 & 0.40 \\
\hline$S=3$ & 0.99 & 0.94 & 0.85 & 0.75 & 0.73 & 0.64 & 0.59 & 0.54 & 0.52 & 0.41 \\
\hline$S=4$ & 0.88 & 0.82 & 0.76 & 0.66 & 0.65 & 0.52 & 0.49 & 0.46 & 0.43 & 0.32 \\
\hline
\end{tabular}

\section{Post-war sample 1950 - 2009}

Size portfolios

\begin{tabular}{|c|c|c|c|c|c|c|c|c|c|}
\hline $\mathrm{S} 1$ & $\mathrm{~S} 2$ & $\mathrm{~S} 3$ & $\mathrm{~S} 4$ & $\mathrm{~S} 5$ & S6 & S7 & S8 & S9 & $\mathrm{S} 10$ \\
\hline \multicolumn{10}{|c|}{ Mean excess returns } \\
\hline 11.5 & 10.4 & 10.3 & 9.8 & 10.0 & 8.9 & 9.4 & 8.6 & 8.0 & 6.6 \\
\hline \multicolumn{10}{|c|}{ Variances of excess returns } \\
\hline 9.0 & 6.7 & 5.3 & 5.3 & 4.7 & 4.0 & 3.8 & 3.2 & 2.7 & 2.9 \\
\hline
\end{tabular}

Horizon

$S=0^{*}$

Consumption growth covariances

$\begin{array}{lllllllllll}S=0 & 0.00 & -0.01 & -0.01 & -0.01 & 0.00 & -0.01 & -0.01 & -0.01 & -0.01 & 0.00\end{array}$

$\begin{array}{lllllllllll}S=1 & 0.14 & 0.12 & 0.10 & 0.10 & 0.11 & 0.08 & 0.08 & 0.08 & 0.06 & 0.07\end{array}$

$\begin{array}{lllllllllll}S=2 & 0.15 & 0.12 & 0.10 & 0.10 & 0.10 & 0.07 & 0.06 & 0.07 & 0.05 & 0.06\end{array}$

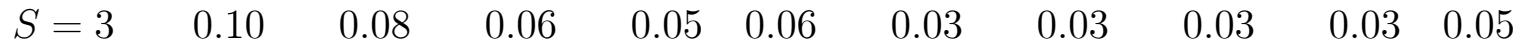

$\begin{array}{lllllllllll}S=4 & 0.09 & 0.06 & 0.04 & 0.03 & 0.04 & 0.01 & 0.00 & 0.02 & 0.01 & 0.04\end{array}$

The table reports mean and variance of excess returns (in \%) as well as covariances of consumption growth rates with the portfolios: $100 \times \operatorname{cov}\left(\frac{C_{t+S}}{C_{t-1}}, R_{i, t}^{e}\right)$. We indicate with a star, "*", when we use beginning-of-period consumption rather than standard end-ofperiod consumption. 'S1' to 'S10' are ten portfolios formed on size, with S1 containing the smallest firms and S10 containing the largest firms. 
Table 3. Summary statistics for value-based portfolios

\begin{tabular}{|c|c|c|c|c|c|c|c|c|c|c|}
\hline & \multicolumn{10}{|c|}{ Great Depression sample 1926 - 2009} \\
\hline & BM1 & BM2 & BM3 & BM4 & BM5 & BM6 & BM7 & BM8 & BM9 & BM10 \\
\hline & \multicolumn{10}{|c|}{$\underline{\text { Mean excess returns }}$} \\
\hline & 6.9 & 7.9 & 7.7 & 7.6 & 9.2 & 9.5 & 9.6 & 11.7 & 12.3 & 13.1 \\
\hline & \multicolumn{10}{|c|}{$\underline{\text { Variances of excess returns }}$} \\
\hline & 5.1 & 3.7 & 3.8 & 4.8 & 5.0 & 5.4 & 5.9 & 7.0 & 7.9 & 10.8 \\
\hline$\underline{\text { Horizon }}$ & \multicolumn{10}{|c|}{ Consumption growth covariances } \\
\hline$S=0^{*}$ & 0.29 & 0.26 & $0 . \overline{25}$ & 0.28 & 0.28 & 0.34 & 0.30 & 0.32 & 0.37 & 0.40 \\
\hline$S=0$ & 0.07 & 0.03 & 0.04 & 0.08 & 0.08 & 0.18 & 0.10 & 0.11 & 0.10 & 0.09 \\
\hline$S=1$ & 0.36 & 0.30 & 0.29 & 0.37 & 0.36 & 0.52 & 0.40 & 0.44 & 0.47 & 0.49 \\
\hline$S=2$ & 0.44 & 0.33 & 0.36 & 0.44 & 0.42 & 0.62 & 0.50 & 0.55 & 0.61 & 0.68 \\
\hline$S=3$ & 0.43 & 0.33 & 0.36 & 0.50 & 0.47 & 0.65 & 0.59 & 0.66 & 0.68 & 0.82 \\
\hline$S=4$ & 0.32 & 0.24 & 0.26 & 0.41 & 0.38 & 0.58 & 0.52 & 0.61 & 0.58 & 0.74 \\
\hline
\end{tabular}

Post-war sample 1950 - 2009

Value portfolios

\begin{tabular}{|c|c|c|c|c|c|c|c|c|c|}
\hline BM1 & BM2 & BM3 & BM4 & BM5 & BM6 & BM7 & BM8 & BM9 & BM10 \\
\hline
\end{tabular}

$\begin{array}{llllllllll}6.1 & 6.8 & 7.4 & 7.2 & 8.9 & 8.8 & 9.0 & 11.0 & 11.1 & 12.5\end{array}$

Variances of excess returns

$\begin{array}{llllllllll}4.1 & 2.7 & 2.9 & 2.9 & 3.1 & 2.7 & 3.3 & 4.2 & 4.1 & 5.6\end{array}$

$\underline{\text { Horizon }} \quad$ Consumption growth covariances

$\begin{array}{lllllllllll}S=0 * & 0.08 & 0.07 & 0.07 & 0.05 & 0.06 & 0.07 & 0.07 & 0.09 & 0.09 & 0.13\end{array}$

$\begin{array}{lllllllllll}S=0 & -0.01 & -0.02 & -0.02 & -0.01 & 0.00 & 0.00 & 0.00 & 0.01 & 0.00 & 0.02\end{array}$

$\begin{array}{lllllllllll}S=1 & 0.07 & 0.06 & 0.05 & 0.04 & 0.05 & 0.07 & 0.08 & 0.10 & 0.10 & 0.15\end{array}$

$\begin{array}{lllllllllll}S=2 & 0.05 & 0.05 & 0.04 & 0.03 & 0.04 & 0.07 & 0.09 & 0.10 & 0.10 & 0.15\end{array}$

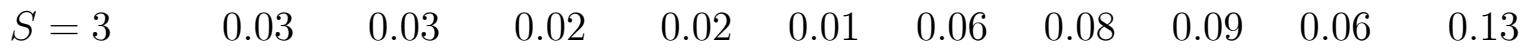

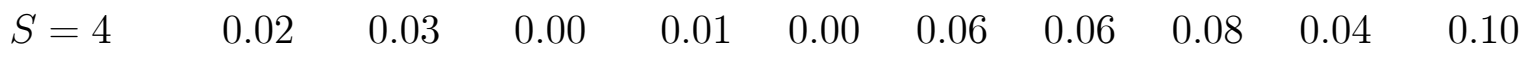

'BM1' to 'BM10' are ten portfolios sorted on book-to-market, with BM1 containg the firms with the lowest book-to-market values, and BM10 containing the firms with the highest book-to-market values. Otherwise, see the notes to Table 2. 
Table 4. Summary statistics for industry sorted portfolios



\section{Post-war sample 1950 - 2009}

Industry portfolios

NoDur Durbl Manuf Enrgy HiTex Telcm Shops Hlth Utils Other

\section{Mean excess returns}

$\begin{array}{llllllllll}8.5 & 7.8 & 7.1 & 9.0 & 9.2 & 6.2 & 8.3 & 9.8 & 6.6 & 8.0\end{array}$

Variances of excess returns

$\begin{array}{llllllllll}2.9 & 6.1 & 3.2 & 3.6 & 6.7 & 3.4 & 4.7 & 4.2 & 2.5 & 4.0\end{array}$

\begin{tabular}{lrrrrrrrrrr} 
Horizon & \multicolumn{7}{c}{ Consumption growth covariances } \\
$S=0^{*}$ & 0.05 & 0.14 & 0.08 & 0.03 & 0.13 & 0.05 & 0.10 & 0.03 & 0.03 & 0.08 \\
$S=0$ & -0.04 & -0.01 & 0.00 & 0.03 & 0.01 & -0.01 & -0.04 & -0.03 & -0.01 & -0.01 \\
$S=1$ & 0.02 & 0.13 & 0.08 & 0.06 & 0.14 & 0.05 & 0.06 & 0.00 & 0.02 & 0.07 \\
$S=2$ & 0.01 & 0.16 & 0.06 & 0.01 & 0.15 & 0.04 & 0.09 & -0.03 & 0.02 & 0.07 \\
$S=3$ & 0.00 & 0.17 & 0.03 & -0.03 & 0.15 & 0.03 & 0.07 & -0.05 & 0.00 & 0.06 \\
$S=4$ & 0.00 & 0.15 & 0.01 & -0.05 & 0.12 & 0.02 & 0.07 & -0.03 & -0.01 & 0.05 \\
\hline
\end{tabular}

See the notes to Table 2. 
Tabel 5. GMM estimation of the model based on 10 size portfolios joint with 10 industry portfolios

\begin{tabular}{|c|c|c|c|c|c|c|c|}
\hline \multirow[b]{2}{*}{ Horizon } & \multicolumn{7}{|c|}{ Great Depression sample 1926 - 2009} \\
\hline & $\gamma$ & $\operatorname{se}(\gamma)$ & $\alpha$ & $\operatorname{se}(\alpha)$ & $R^{2}(\%)$ & J-stat & P-value \\
\hline$S=0^{*}$ & 15.4 & 8.3 & 0.027 & 0.036 & 74 & 28.6 & 0.05 \\
\hline$S=0$ & -1.2 & 14.5 & 0.100 & 0.028 & 0 & 33.5 & 0.01 \\
\hline$S=1$ & 10.1 & 7.0 & 0.027 & 0.040 & 57 & 37.5 & 0.00 \\
\hline$S=2$ & 7.1 & 4.3 & 0.028 & 0.038 & 70 & 37.4 & 0.00 \\
\hline$S=3$ & 5.2 & 3.4 & 0.043 & 0.032 & 81 & 46.6 & 0.00 \\
\hline \multirow[t]{2}{*}{$S=4$} & 4.9 & 3.4 & 0.059 & 0.030 & 76 & 50.4 & 0.00 \\
\hline & \multicolumn{7}{|c|}{ Post-war sample 1950 - 2009} \\
\hline Horizon & $\gamma$ & $\operatorname{se}(\gamma)$ & $\alpha$ & $\operatorname{se}(\alpha)$ & $R^{2}(\%)$ & J-stat & $\mathrm{P}$-value \\
\hline$S=0^{*}$ & 16.7 & 24.7 & 0.073 & 0.023 & 21 & 32.3 & 0.02 \\
\hline$S=0$ & -1.0 & 42.5 & 0.087 & 0.023 & 0 & 36.2 & 0.01 \\
\hline$S=1$ & 10.1 & 20.7 & 0.079 & 0.022 & 16 & 52.8 & 0.00 \\
\hline$S=2$ & 6.4 & 14.1 & 0.083 & 0.018 & 16 & 57.6 & 0.00 \\
\hline$S=3$ & 1.9 & 10.3 & 0.087 & 0.017 & 6 & 71.5 & 0.00 \\
\hline$S=4$ & 1.4 & 10.0 & 0.088 & 0.017 & 2 & 141.5 & 0.00 \\
\hline
\end{tabular}

The table reports GMM estimates of relative risk aversion $(\gamma)$ and the average pricing error $(\alpha)$, as well as corresponding standard errors. The table also reports the crosssectional explanatory power $\left(R^{2}\right)$, Hansen's test of overidentifying restrictions ('J-stat', which is asymptotically $\chi^{2}$ distrubuted with $N+1-3=18$ degrees of freedom since $N=20$ ), and its corresponding p-value ('P-value'). We indicate with a star, "*", when we use beginning-of-period consumption rather than standard end-of-period consumption. 
Tabel 6. GMM estimation of the model based on 10 value portfolios joint with 10 industry portfolios

\begin{tabular}{lccccccc}
\hline & \multicolumn{8}{c}{ Great Depression sample 1926-2009 } \\
Horizon & $\gamma$ & $\mathrm{se}(\gamma)$ & $\alpha$ & $\mathrm{se}(\alpha)$ & $R^{2}(\%)$ & $\mathrm{J}$-stat & P-value \\
\hline$S=0^{*}$ & 14.2 & 8.3 & 0.032 & 0.026 & 52 & 39.8 & 0.00 \\
$S=0$ & 12.1 & 8.8 & 0.073 & 0.024 & 4 & 43.3 & 0.00 \\
$S=1$ & 8.2 & 5.8 & 0.040 & 0.023 & 43 & 41.8 & 0.00 \\
$S=2$ & 5.8 & 3.9 & 0.039 & 0.024 & 60 & 57.9 & 0.00 \\
$S=3$ & 4.9 & 3.3 & 0.046 & 0.024 & 68 & 82.5 & 0.00 \\
$S=4$ & 4.5 & 3.2 & 0.062 & 0.026 & 64 & 112.8 & 0.00 \\
\hline \multicolumn{8}{c}{ Post-war sample 1950- 2009 } \\
\hline$S=0^{*}$ & 16.1 & 21.4 & 0.072 & 0.022 & 12 & 48.3 & 0.00 \\
$S=0$ & 28.5 & 37.0 & 0.085 & 0.025 & 21 & 52.1 & 0.00 \\
$S=1$ & 16.7 & 16.4 & 0.072 & 0.024 & 28 & 50.9 & 0.00 \\
$S=2$ & 10.8 & 10.9 & 0.079 & 0.019 & 23 & 63.4 & 0.00 \\
$S=3$ & 6.9 & 8.8 & 0.083 & 0.018 & 12 & 95.7 & 0.00 \\
$S=4$ & 6.3 & 9.0 & 0.083 & 0.017 & 10 & 103.6 & 0.00 \\
\hline
\end{tabular}

See the notes to Table 5 . 
Tabel 7. GMM estimation of the model based on 6 size and value portfolios joint with 5 industry portfolios

\begin{tabular}{|c|c|c|c|c|c|c|c|}
\hline \multirow[b]{2}{*}{ Horizon } & \multicolumn{7}{|c|}{ Great Depression sample 1926 - 2009} \\
\hline & $\gamma$ & $\operatorname{se}(\gamma)$ & $\alpha$ & $\operatorname{se}(\alpha)$ & $R^{2}(\%)$ & J-stat & P-value \\
\hline$S=0^{*}$ & 17.2 & 8.4 & 0.014 & 0.035 & 54 & 40.2 & 0.00 \\
\hline$S=0$ & 24.3 & 10.2 & 0.035 & 0.068 & 7 & 39.3 & 0.00 \\
\hline$S=1$ & 11.0 & 6.8 & 0.015 & 0.041 & 46 & 45.7 & 0.00 \\
\hline$S=2$ & 7.3 & 4.2 & 0.020 & 0.037 & 56 & 53.8 & 0.00 \\
\hline$S=3$ & 6.1 & 3.6 & 0.028 & 0.038 & 64 & 60.7 & 0.00 \\
\hline \multirow[t]{2}{*}{$S=4$} & 5.5 & 3.4 & 0.051 & 0.034 & 60 & 74.8 & 0.00 \\
\hline & \multicolumn{7}{|c|}{ Post-war sample 1950 - 2009} \\
\hline Horizon & $\gamma$ & $\operatorname{se}(\gamma)$ & $\alpha$ & $\operatorname{se}(\alpha)$ & $R^{2}(\%)$ & J-stat & $\mathrm{P}$-value \\
\hline$S=0^{*}$ & 33.7 & 30.4 & 0.060 & 0.030 & 14 & 33.8 & 0.00 \\
\hline$S=0$ & 19.6 & 38.3 & 0.091 & 0.025 & 2 & 33.9 & 0.00 \\
\hline$S=1$ & 24.3 & 21.1 & 0.070 & 0.032 & 16 & 33.5 & 0.00 \\
\hline$S=2$ & 25.1 & 14.2 & 0.075 & 0.023 & 30 & 31.0 & 0.00 \\
\hline$S=3$ & 22.0 & 12.0 & 0.086 & 0.019 & 20 & 45.9 & 0.00 \\
\hline$S=4$ & 24.4 & 15.2 & 0.084 & 0.017 & 18 & 71.9 & 0.00 \\
\hline
\end{tabular}

See the notes to Table 5 . Here the 'J-test' has $N+1-3=9$ degrees of freedom since $N=11$. 

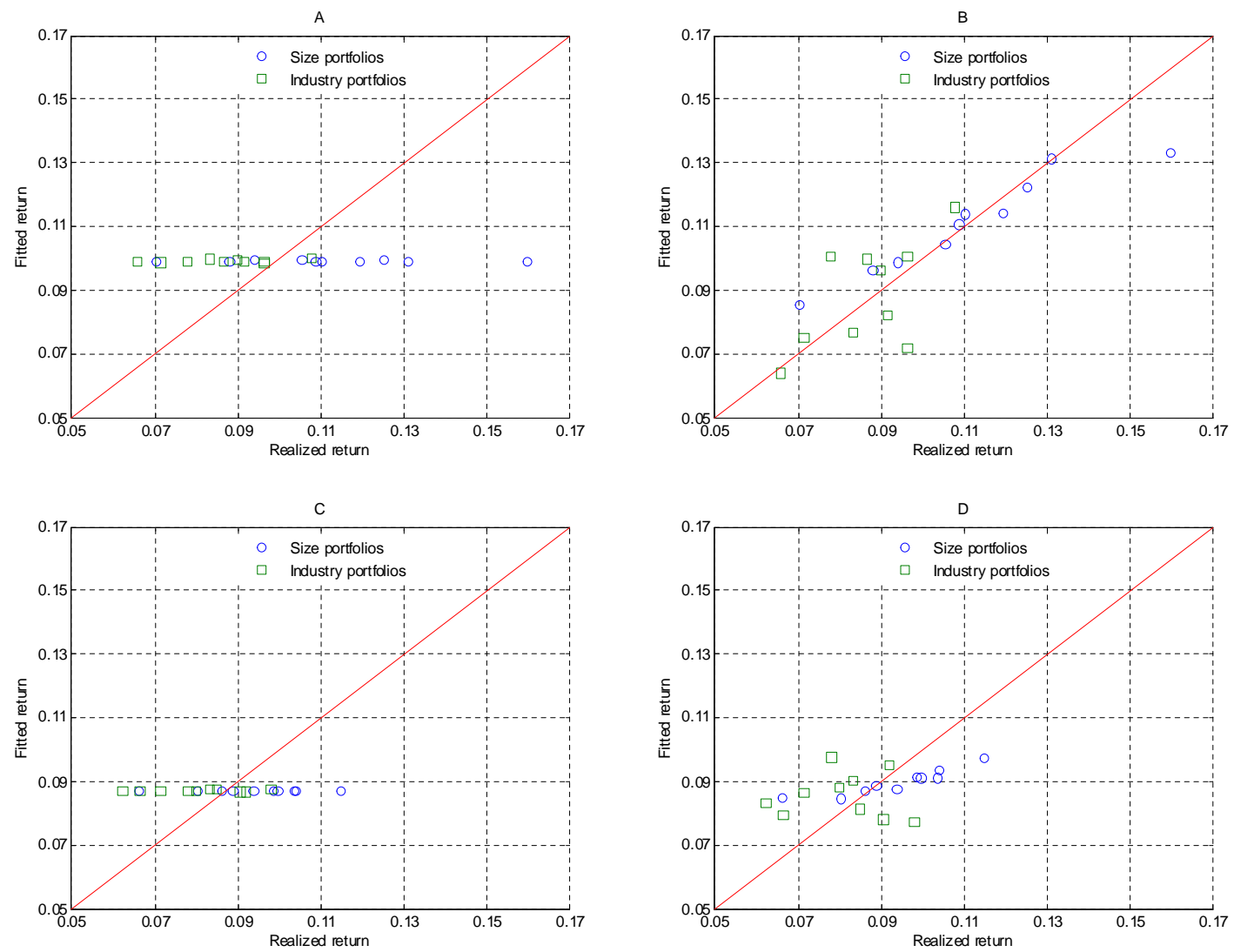

Figure 1. Realized vs. fitted returns on size- and industry-sorted portfolios. A: Great Depression sample with $S=0$. B: Great Depression sample with $S=0^{*}$. C: Post-war sample with $S=0$. D: Post-war sample with $S=0^{*}$. The Great Depression sample covers the period 1926-2009, while the Post-war sample covers the period 1950-2009. 

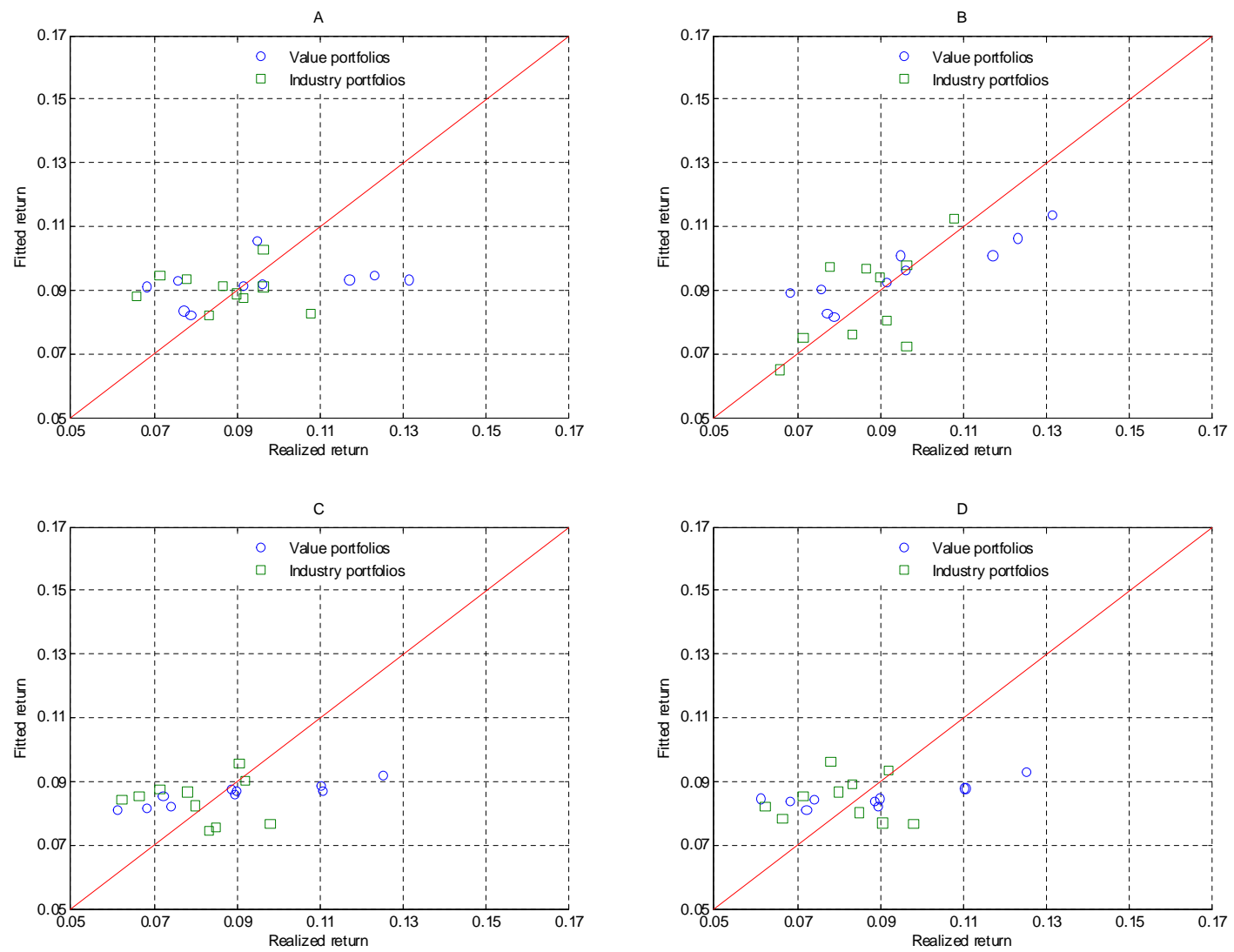

Figure 2. Realized vs. fitted returns on value- and industry-sorted portfolios. A: Great Depression sample with $S=0$. B: Great Depression sample with $S=0 *$. C: Postwar sample with $S=0$. D: Post-war sample with $S=0^{*}$. The Great Depression sample covers the period 1926-2009, while the Post-war sample covers the period 1950-2009. 
2010-69: Søren J ohansen: The analysis of nonstationary time series using regression, correlation and cointegration -with an application to annual mean temperature and sea level

2010-70: $\quad$ Søren J ohansen and Morten Ørregaard Nielsen: A necessary moment condition for the fractional functional central limit theorem

2010-71: Nektarios Aslanidis and Isabel Casas : Modelling asset correlations during the recent financial crisis: A semiparametric approach

2010-72: Søren J ohansen and Katarina J uselius: An invariance property of the common trends under linear transformations of the data

2010-73: $\quad$ Peter Sandholt J ensen and Allan H. Würtz: Estimating the effect of a variable in a high-dimensional regression model

2010-74: $\quad$ Peter R. Hansen, Asger Lunde and Valeri Voev: Realized Beta GARCH: A Multivariate GARCH Model with Realized Measures of Volatility and CoVolatility

2010-75: $\quad$ Laurent A.F. Callot: A Bootstrap Cointegration Rank Test for Panels of VAR Models

2010-76: Peter R. Hansen, Asger Lunde and J ames M. Nason: The Model Confidence Set

2011-01: Cristina Amado and Timo Teräsvirta: Modelling Volatility by Variance Decomposition

2011-02: Timo Teräsvirta: Nonlinear models for autoregressive conditional heteroskedasticity

2011-03: Roxana Halbleib and Valeri Voev: Forecasting Covariance Matrices: A Mixed Frequency Approach

2011-04: Mark Podolskij and Mathieu Rosenbaum: Testing the local volatility assumption: a statistical approach

2011-05: Michael Sørensen: Prediction-based estimating functions: review and new developments

2011-06: Søren J ohansen: An extension of cointegration to fractional autoregressive processes

2011-07: Tom Engsted and Stig V. Møller: Cross-sectional consumption-based asset pricing: The importance of consumption timing and the inclusion of severe crises 